\title{
Review Article \\ The Effects of Surface Properties of Nanostructured Bone Repair Materials on Their Performances
}

\author{
Feng Zhao, ${ }^{1}$ Jian Wang, ${ }^{1}$ Hongjuan Guo, ${ }^{2}$ Shaojun Liu, ${ }^{1}$ and Wei $\mathrm{He}^{3}$ \\ ${ }^{1}$ Department of Orthopedics, The First Hospital of Hebei Medical University, Shijiazhuang 050031, China \\ ${ }^{2}$ Department of Outpatient Service Office, The First Hospital of Hebei Medical University, Shijiazhuang 050031, China \\ ${ }^{3}$ Department of Hand Surgery, The Third Hospital of Hebei Medical University, Shijiazhuang 050051, China
}

Correspondence should be addressed to Wei He; love_v@126.com

Received 3 November 2014; Accepted 16 December 2014

Academic Editor: Shuming Zhang

Copyright (C) 2015 Feng Zhao et al. This is an open access article distributed under the Creative Commons Attribution License, which permits unrestricted use, distribution, and reproduction in any medium, provided the original work is properly cited.

\begin{abstract}
Nanotechnology has been expected to be an extraordinarily promising method for bone repair. Meanwhile, the promise of nanobiomaterials for therapeutic applications has been widely reported, and a lot of studies have been made in terms of repairing bone using nanomaterials accompanied by rapid development of nanotechnology. Compared with conventional biomaterials, nanostructured implants have been shown to possess positive effects on cellular functions because of their unique surface properties, such as nanotopography, increased wettability, larger surface area, and microenvironment similar to extracellular matrix. Moreover, many positive cellular responses have been found to take place at the interface between nanostructured implants and host bone. In this paper, we will give a review about the effects of surface properties of nanostructured bone repair materials on their performances in terms of several aspects and a detailed interpretation or introduction on the specific cellular recognitions at the interface between nanostructured implants and host bone.
\end{abstract}

\section{Introduction}

With the increase in the elderly population, the need for orthopedic implants is growing at an increasing speed. Before, allografts and autografts are common methods to cure bone defects. However, great limitation exists in the above measure; for instance, as with autografts, autologous bone regeneration does not possess enough strength to support the whole body $[1,2]$. At present, synthetic implants are most employed in bone repair, but some drawbacks, such as fatigue, fracture, lack of biocompatibility, restrict its implication greatly on a larger scale. It is the hope that these materials will repair bone quickly and effectively so that the patient can return to a normal healthy life style. However, it has been estimated that the service life of present implant materials used today as bone fixation ranges from 10 to 15 years $[3,4]$. Such limited lifetime is absolutely not good news for more and more patients, especially young patients. Short service life will cause secondary damage to their body. It is necessary to create a novel bone implant, which could offer a framework for regenerating and healing the host bone and blood vessel instead of replacing missing bone temporarily. In other words, an ideal implant should at least consist of two points as follows: interacting with the host tissue well and promoting differentiation of osteogenic cells (Figure 1).

As to the common implantation, once implanted into body under the condition of surrounding tissue, the common implantations are apt to get loosened under physiological loading conditions, thus leading to implant failure in the end. In the final analysis, the osseointegration between implant materials and bone tissue was not formed really was responsible for the loose phenomenon "into" was not formed really as a result of implantations' loosening. Therefore, the success of both the orthopedic implant and the tissue engineered construct is highly dependent on the selected biomaterial. One of the key factors identified in the failure of both types of implants was insufficient tissue regeneration around the biomaterial immediately after implantation. It is known that the introduction of an implant into a living organism causes specific reactions in the biological environment. The biomolecules and cells together with the intrinsic properties 

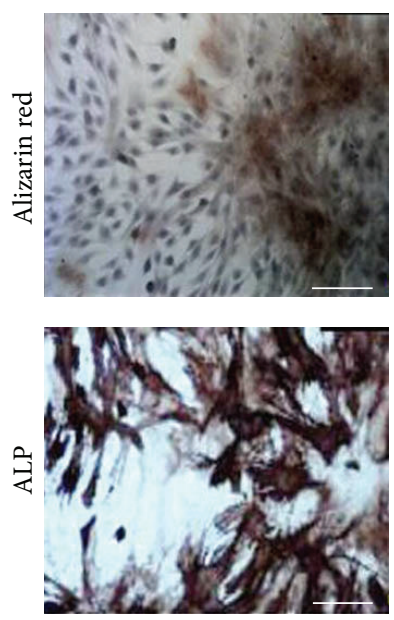

(a)
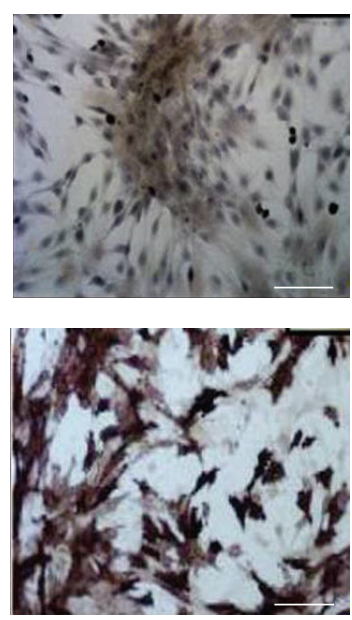

(b)
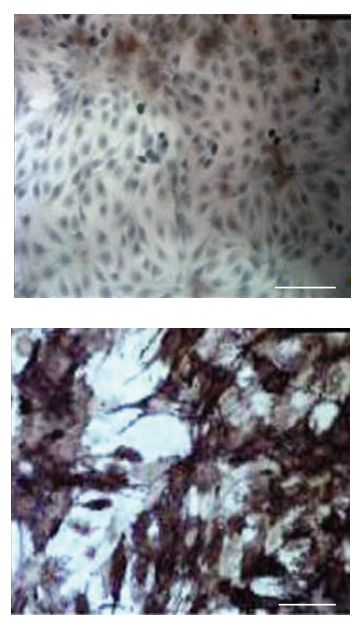

(c)
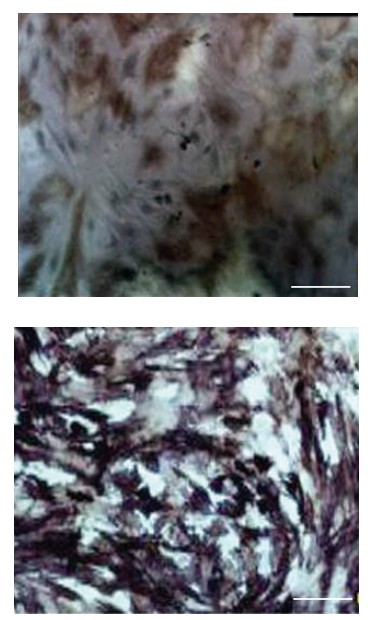

(d)

FIGURE 1: Histological and chemical characterization of hMSCs cultured on different films with varying surface roughness. ALP activity as a marker of early osteoblastic differentiation displayed activity in all films. The content of calcium could be stained by Alizarin Red. Compared with other films, the roughest film could significantly promote the differentiation of hMSCs in the direction of osteoblasts (size of surface roughness: (a) < (b) < (c) < (d), and scale bars stand for $200 \mu \mathrm{m})$. (Adapted with permission from [5]. Copyright 2011 Elsevier Ltd).

of the chosen biomaterials determine the biocompatibility and longevity of the implants. Since the interaction of those biomolecules and cells with the biomaterial surface is a vital element in the evaluation of the biomaterial, biomaterial scientists have reexamined the pertinent host-cell interactions in order to design materials that facilitate favorable interactions and enhance tissue regeneration. Ultimately, improved symbiosis should result in an accelerated healing time, increase in implant longevity, and a reduction in the necessity for revision surgery.

With the tremendous development of nanotechnology in material science and engineering, biomedical engineering becomes the most promising and challenging field involved in the application of nanostructured materials [6-17]. Nanotechnology represents the manner to manipulation atoms and molecules over the scale of nanometer and generates the materials with at least one dimension in nanoscale. In comparison to the bulk material, the nanomaterials possess many specific characteristics due to the "quantum mechanical effect" [18-20]. Moreover, research has shown that all living systems are governed by molecular behavior at nanometer scales. The molecular building blocks of life proteins, nucleic acids, lipids, and carbohydrates are examples of materials that possess unique properties determined by the size, folding, and patterns at the nanoscale. Also, the surface properties of nanostructured implant structure are similar to extracellular matrix (ECM) to a great extent. For all the above reasons, cells in our body are predisposed to interact with nanostructured surfaces [21]. Consequently, to perform a surface modification at nanolevel will offer a better matrix for osteoblasts to grow and to function in theory. For example, osteoblasts on nanosized Ti, Ti6Al4V powder-modified metal surfaces have improved adhesion and functions when compared to macrophase ones [22-24]. To further improve and optimize the properties of the existing nanostructured implants for biomedical devices and adapt more desired nanostructured devices with desirable surface characteristics, modifications of nanostructured implants for biomedical application are essential [25-29]. In the paper, we will give a detailed interpretation on the nonspecific cellular recognition in the interface of nanostructured implant surfaces and defected bone; what is more, the effect of the surface property of nanostructured implant on bone repair, such as nanotopography, surface chemistry, and hydrophilic and hydrophobic properties, will be introduced in terms of several aspects. Overall, we believe, through the particular nanoscale modification on the surface of implants, nanostructured implant shows a bright future in the treatment of bone repair.

\section{Nanostructured Implant Surfaces' Cellular Recognition}

In terms of designing an ideal implant and controlling the nanostructured implants' surface, the mechanism of recognition between cells and nanostructured implant surfaces plays an extremely vital role. For purpose of having a good understanding of the interaction between the surface of nanostructured implant and bone under biological environment, more detailed research should be conducted. Additionally, the preparation method of implants with needed nanomorphology and other surface properties should also be studied correspondingly. Provided that we have a well knowledge of not only the mechanism of cellular recognition and nanostructured implant surfaces, but also preparation method of various desirable nanostructured implants, it will provide a possibility to regulate anticipated biological effects by means of controlling the surface nanostructure of implants. Every effort has been made to investigate how to design nanostructured implants to promote desirable responses from surrounding cells for better osseointegration. 


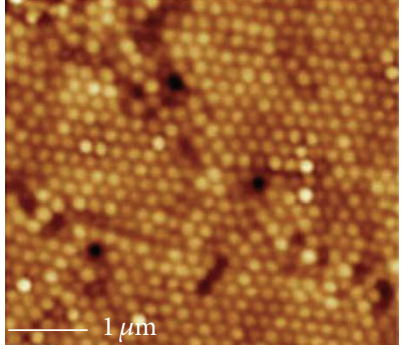

(a)

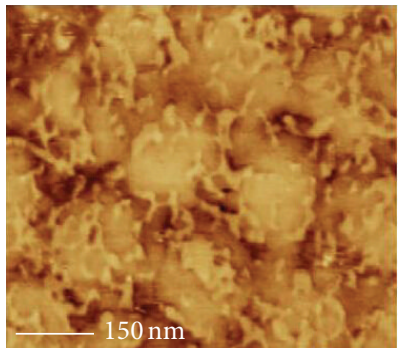

(b)

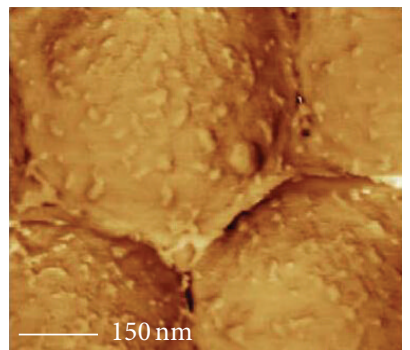

(c)

Figure 2: AFM images of fibronectin coated PLGA cast nanosphere surfaces. (a) PLGA with $200 \mathrm{~nm}$ surface features only. (b) Phase images of fibronectin adsorbed on PLGA with $200 \mathrm{~nm}$ surface features showed significant interconnectivity between fibronectins. (c) Phase images of fibronectin adsorbed on PLGA with $500 \mathrm{~nm}$ surface features showed no interconnectivity between proteins. (Adapted with permission from [34]. Copyright 2008 Elsevier Ltd).

It has been proved that proteins will be adsorbed from bodily fluids such as bone marrow, blood, and other tissues prior to cell adhesion (such as osteoblasts). Moreover, specific proteins (such as fibronectin and vitronectin) in biological fluids, such as blood plasma, mediate the adhesion, differentiation, and growth of desirable cells on an implant surface [30] (Figure 2). For this reason, many investigators are now paying close attention to manipulating initial protein adsorption events by altering selected properties of implant surfaces. In the study of introducing stainless steel hydroxyapatite ceramics into composites, Tulinski and Jurczyk hold the viewpoint that nanocrystalline nickel-free stainless steels and nickel-free stainless steel/hydroxyapatite nanocomposites could be promising bionanomaterials for use as hard tissue replacement implants; what is more, they considered that the surface roughness and the surface topography influenced the proliferation of cells [31]. Gagner et al. [32] made a relatively intensive study about the control of protein adsorption and subsequent biological outcomes by regulating the surface of nanoparticles. Chun and Webster considered that the incorporation of inorganic nanomaterials into the biological environment is necessary. Implant structures (such as orthopedic prosthetics) have been shown to benefit greatly from nanostructured surfaces that could promote osteoblasts integration and limit bacterial adhesion and inflammation, while matching the material properties of the surrounding bone system at the same time [33].

Peng et al. summarized the nanostructured materials currently used in musculoskeletal tissue engineering including natural polymers, synthetic polymers, and inorganic materials [35]. Moreover, nanostructured materials can be synthesized with controlled composition, size, geometry, and morphology. Most importantly, they deemed that, by means of modifying the surface of these materials, it could enhance biocompatibility, immune compatibility, and cell adhesion of nanostructured materials for different applications in musculoskeletal tissue scaffolds.

Exactly, changes in implant surface energy, surface chemical composition, and topographical features influence the type and concentration of adsorbed proteins [36]. Accordingly, the efficacy of bone regeneration is determined mainly by surface characteristics such as the chemical composition and physical properties of the implant that controls initial protein adsorption, which could mediate cells adhesion. Together, this is this new direction aimed at intelligently designing implant surfaces to control protein interactions important for subsequent cell adhesion that may provide answers to those problems which have plagued current orthopedic implants. The core of all the issue is to alter the surface chemistries and nanotopographies of orthopedic implant in nanoscale.

\section{The Factors of Surface Property of Nanostructured Implant}

Through the above description, we could make sense that the nanotopography and surface properties of nanostructured implant determine the response of cells. Several factors, such as nanotopography, hydrophilic and hydrophobic properties, and surface chemistry, greatly affect the growth of bone on the implants; moreover, the above influence factors have been focused on the terms of enhanced orthopedic implant $[37,38]$.

3.1. Nanotopography. How to optimize cell recognition and response by modified nanotopography is the focus of discussion in orthopedic tissue engineering $[39,40]$, since nanotopography of implants has been considered to have great effect on both proliferation and differentiation of osteoblastic cells. The properties of substrate have a great effect on cells' response [41]. For the purpose of forming specific nanotopography on substrate, several means should be employed. For instance, Lee et al. successfully prepared titanium alloy with nanohydroxyapatite coatings on using an electrochemical deposition method [42] (Figure 3). A novel model system for studying the influence of nanoscale surface properties on the osseointegration in rat tibia was created by Ballo et al. [43]. They conducted the histological evaluation on the ground sections at 7 days and 28 days after implantation. In their study, the main distinction appeared in the process of formation of new bone in the marrow bone compartments after 28 days of implantation. In comparison with $120 \mathrm{~nm}$ and control surfaces, implant surfaces with $60 \mathrm{~nm}$ features took 


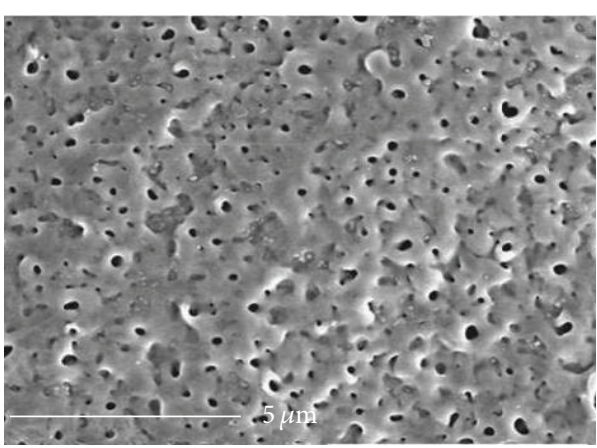

(a)

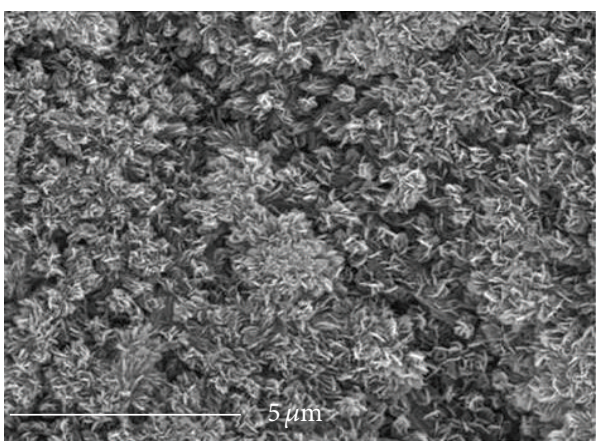

(c)

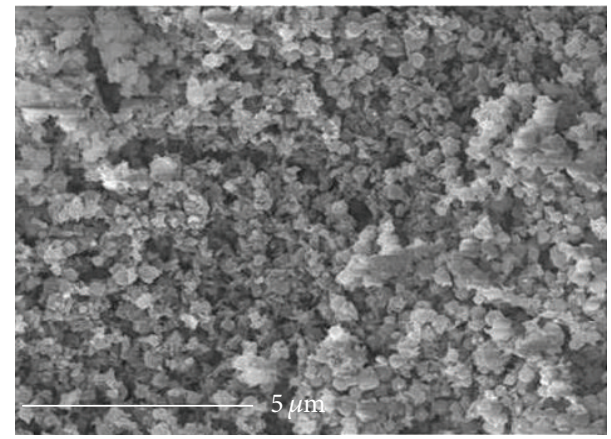

(b)

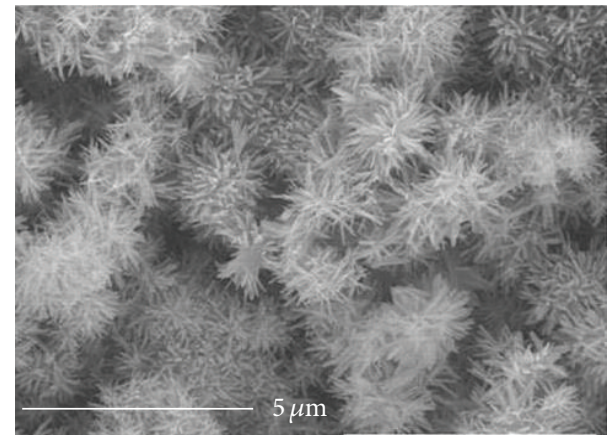

(d)

FIGURE 3: FE-SEM images of nanophase hydroxyapatite coatings deposition on anodized Ti with increases in deposition time in the electrolyte at $85^{\circ} \mathrm{C}$ : (a) initial anodized commercially pure titanium without hydroxyapatite coatings, (b) $5 \mathrm{~min}$, (c) $30 \mathrm{~min}$, and (d) $60 \mathrm{~min}$ deposition times for hydroxyapatite coatings layer. (Adapted with permission from [42]. Copyright 2013 Elsevier Ltd).

on obviously higher bone-implant contact. They considered that this phenomenon connected with the $60 \mathrm{~nm}$ protrusions, with higher density and curvature. In the end, Ballo et al. considered that the aforementioned model system could actually be applied for the systematic variation of surface nanofeatures density and chemistry, which provided the possibility for research of interactions between various nanoscale surfaces and bones.

Moreover, in order to prove that carbon nanofibers were suitable for bone prosthetic application, carbon nanofibers' cytocompatibility properties and cell adhesion were determined on different cells respectively by Price et al. [44]. For the purpose of determining the enhancement of osteoblasts adhesion in a selective way by nanophase carbon fibers, the cell adhesion assays were conducted on conventional and nanophase carbon fibers compacts by Price et al. By comparison, they concluded that enhanced select osteoblasts adhesion appeared on PLGA casts of nanophase carbon fibers. Most importantly, Price et al. demonstrated that carbon fibers with nanometer dimensions may be more appropriate materials to selectively increase osteoblasts adhesion, which is desperately needed for successful orthopedic/dental implant applications as a result of high degree of nanometer surface roughness. The influence of surface topography of ceramic abutments on the proliferation and attachment of human oral fibroblasts was studied by Mustafa et al. [45]. In accordance with their viewpoints, they considered that, compared to polished surfaces, obviously, more cells were attached to the milled and sintered surfaces after 3 days of cell culture, which demonstrated higher proliferation capacity on those types of surfaces. What is more, with the increase of surface roughness ceramics, the ability to promote initial fibroblast adhesion decreased in comparison with smooth surfaces. Similar trends have been reported for polymers of the same surface chemistry, but only the degree of nanometer surface roughness has been altered [46]. Consequently, different surfaces with nanophase features possess distinct microstructure, thus influencing cells' event [47].

All in all, from the above studies, we could have an understanding that several cells concerned with bone formation are very sensitive to changes in surface roughness features in the nanometer compared with conventional surface; in other words, nanostructured implant could promote the event and response of specific cells obviously (Figure 4). Most importantly, it provides a possibility by means of adjusting surface nanotopography of nanostructured implant to alter cells adsorption and activity.

3.2. Hydrophilic and Hydrophobic Properties. It is widely reported that hydrophilic surface could boost cell adhesion and activity better [48-51]. Consequently, many polymers used for tissue engineering are hydrophobic in their native state and require surface modification or wetting procedures before cell seeding [52]. Wang et al. improved the endothelialization on $316 \mathrm{~L}$ stainless steel by means of altering surface wettability via sol-gel method using tetraethoxysilane 


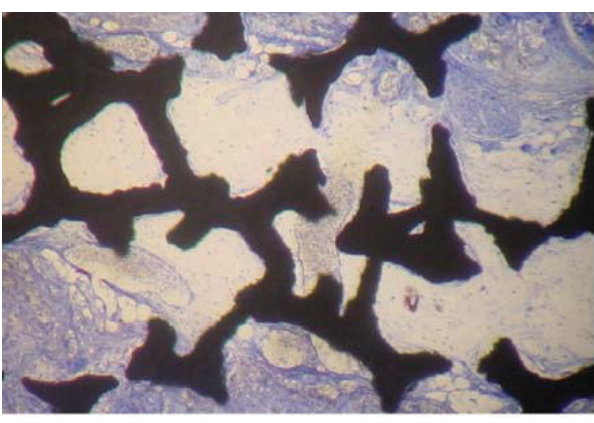

Uncoated scaffold

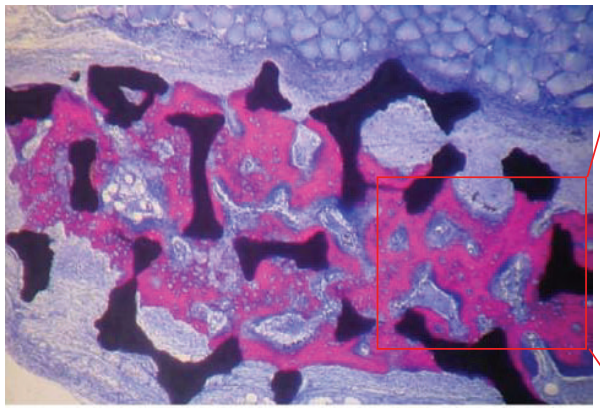

Nano-HA coated scaffolds

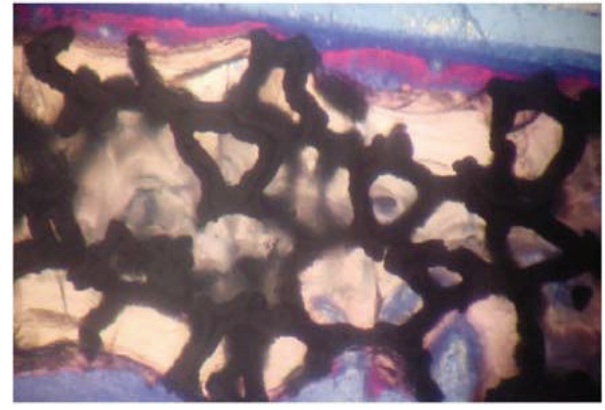

Conventional HA coated scaffolds

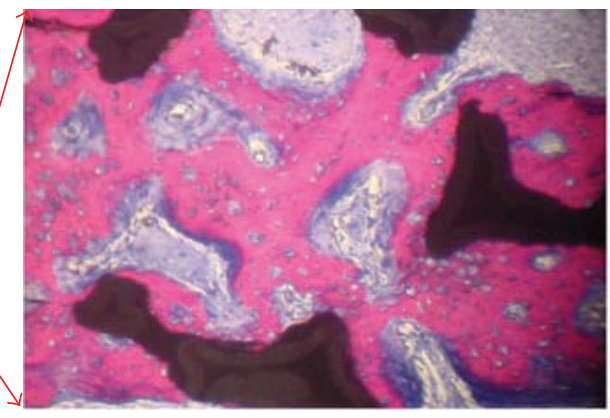

Nano-HA coated scaffolds

(high magnification)

FIGURE 4: Histology of rat calvaria after 6 weeks of implantation of uncoated tantalum, conventional HA coated tantalum, and nanocrystalline HA coated tantalum. Greater amounts of new bone formation occur in the rat calvaria when implanting nanocrystalline HA coated tantalum than uncoated and conventional HA coated tantalum. Red area stands for new bone and blue stands for collagen. (Adapted with permission from [79]. Copyright 2006 Elsevier Ltd).

(TEOS) and methyltriethoxysilane (MTES, Aladdin) as silica precursors, nitric acid and acetic acid as catalysts, and absolute ethanol as solvent [53]. They successfully regulated the hydrophilicity and hydrophobicity of the final coatings by controlling TEOS/MTES molar ratios $(100: 0,70: 30$, and $40: 60$ ) (Figure 5).

Moreover, Webster and colleagues demonstrated that aqueous contact angles were three times smaller when alumina grain size was decreased from 167 to $24 \mathrm{~nm}$. They also reported that the adsorption of vitronectin, which stimulates osteoblasts adhesion, increased on nanophase ceramics with greater wettability. Moreover, when vitronectin adsorbed on nanophase ceramics, it was unfolded to a larger extent than on conventional ceramics, which exposed larger numbers of osteoblasts adhesive epitopes in the absorbed proteins [30]. Similar to ceramics, increased wettability of polymer composites has been achieved through the use of nanophase ceramics in order to increase bone cell function. Specifically, Kay et al. demonstrated that titania nanosized particles embedded in PLGA promoted osteoblast adhesion compared with conventional sized titania in PLGA [54]. On the other word, Macak et al. [55] thought that the signs of the antibodies reduce cell adsorption in the hydrophobic surfaces, while cell adsorption will be stimulated in the hydrophilic surfaces. However, Cai et al. [56] investigated the influence of titanium film micro- and nanoscale topography on protein adsorption and cell growth. However, by means of measuring the content of albumin and fibrinogen adsorption, they found no statistically significant differences in protein adsorption for the films with different topographies. Moreover, no statistically significant influences of surface roughness on osteoblasts proliferation and cell viability were detected in their study. More effective data should be shared with regard to the wettability of nanostructured implant in enhancing the performance of orthopedic implants and we firmly believe that the nanostructured implant will cause desirable cells response and activity by means of modifying the hydrophilic and hydrophobic properties of implants.

3.3. Surface Chemistry. Besides the factors above, implant surface chemistry plays an important role in protein adsorption and subsequent cell adhesion and cell proliferation (Figure 6). Consequently, surface chemistry will also make a difference in the field of implants [57]. As we know, hydroxyapatite (HA) is used in the biomedical industry as the coating for titanium implants. $\mathrm{HA}$ is also used as the structural material for dental, maxillofacial, and orthopedic implants [58]. It has been proved that carbon nanotubes could be used to promote cells' division and proliferation [59-63]. Facca et al. [60] made a research on the osseointegration of nanodesigned composite coatings on titanium implants in vivo. They investigated study of plasma-sprayed carbon nanotubes (CNT) reinforced hydroxyapatite (HA) coating on titanium implants embedded in rodents' bone. No adverse effect or cytotoxicity of CNT addition on bone tissues and cells was observed. Normal bone growth was 


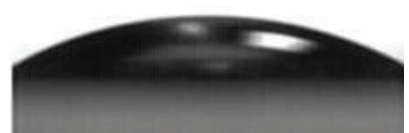

316L: $\theta=26.9^{\circ}$

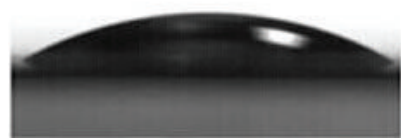

T100: $\theta=26.2^{\circ}$

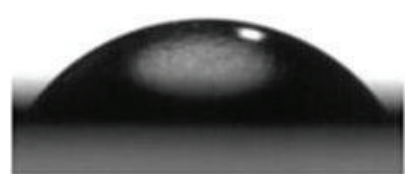

T70M30: $\theta=45.3^{\circ}$

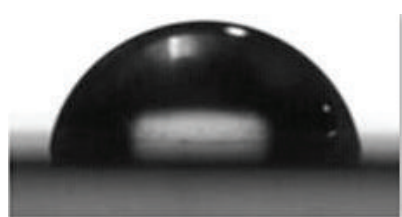

T40M60: $\theta=85.1^{\circ}$

FIGURE 5: Contact angle photographs of a water droplet placed on 316L and other different sol-gel coatings. (Adapted with permission from [53]. Copyright 2012 Elsevier Ltd).
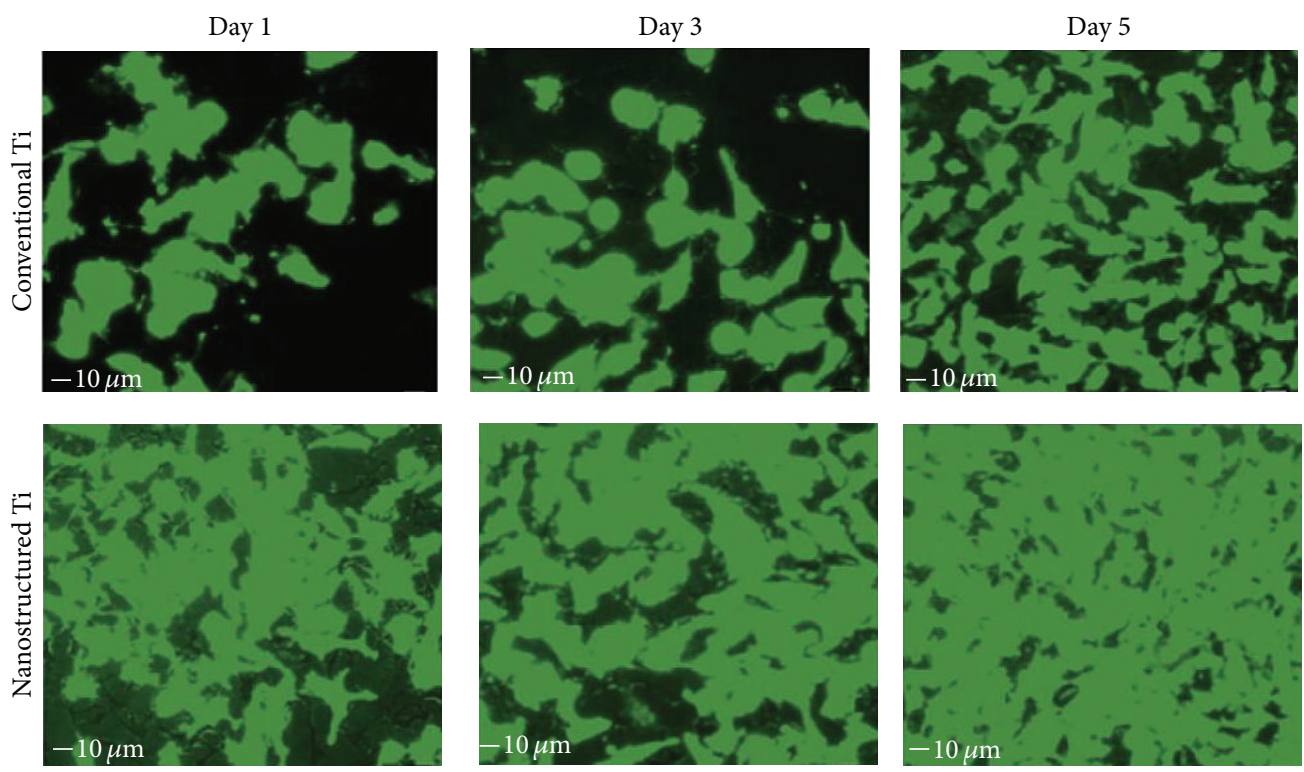

Figure 6: Fluorescent microscopy images of endothelial cell proliferation on nanostructured Ti compared to conventional Ti. (Adapted with permission from [34]. Copyright 2008 Elsevier Ltd).

observed around HA/CNT coated implants. CNT addition induces higher osseointegration as compared to HA. Facca et al. demonstrated that CNT addition resulted in the growth of new bone and improved osseointegration as observed from the adhesion of HA/CNT coating. Moreover, the elastic modulus of the newly grown bone was comparable with the distant bone, suggesting excellent mechanical integrity of the implant, which was consistent with previous studies $[61,62]$. Finally, they considered that longer implantation is needed to further appreciate the quality of osseointegration and to evaluate safety of HA-CNT coating prior to clinical application and the study had a far-reaching significance in orthopedic applications, healing time, and osseointegration.

Besides, titanium oxide in nanoscale with different nanostructures could take on positive effects on growth rates, bone forming, and even acceleration of osteodifferentiation of MSCs [64-70]. Brammer et al. [71] discussed the effects of $\mathrm{TiO}_{2}$ nanotube surfaces for bone regeneration. They considered that the unique 3D tube shaped nanostructure created by electrochemical anodization will have great effects on osteogenic cells and become a very promising method in orthopedic material surface designs. In addition to nanoceramic materials, another kind of commonly used materials in orthopedic implant is medical metals. As to the method of modification of metals implants in nanoscale, various techniques have been employed in creating different topographies on the surface of implants ranging in micron scale [72-74]. Biological activity and events could be boosted in the interface of implants and bone to some extent due to the existence of micron scale surface features [75-78]. However, it is widely acknowledged that the interactions between implants and host tissue could be regulated and controlled by means of nanolevel signal transmission [7981]. That is the reason why various strategies have been devised and implemented to nanoengineered surfaces that can directly influence biological functionalities [79, 82]. For example, Variola et al. [83] discussed the state-of-theart nanotechnology-based approaches currently adopted to modify the surface of metals used for orthopedic and dental applications and also briefly considered their use in the cardiovascular field; moreover, they also debated the effects of nanoengineered surfaces on various in vitro molecular and cellular events and the potential influence of nanotopography on biomechanical events at interfaces. In a word, via the ability of nanostructured surfaces to activate stem cells and accelerate bone formation, bone reconstruction will be completed well without any tissue encapsulation [84-86]; moreover, this will translate into faster healing, improved 

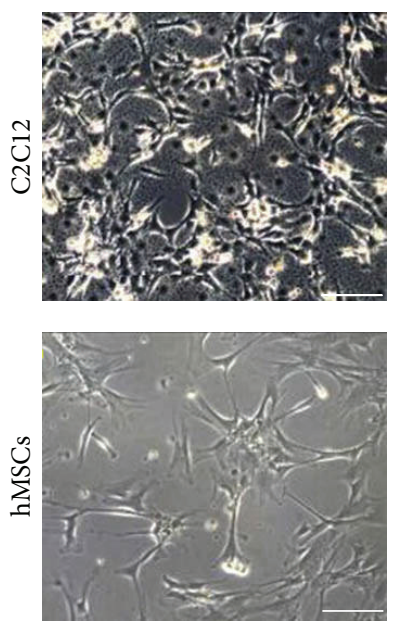

(a)
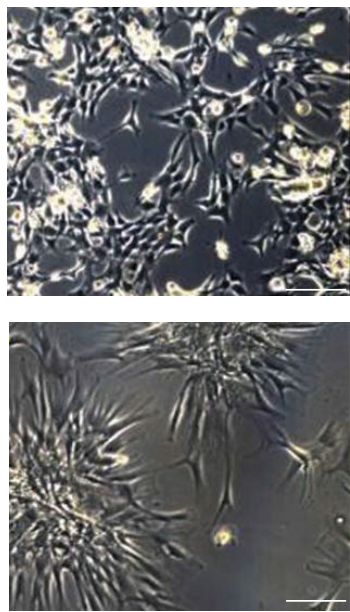

(b)
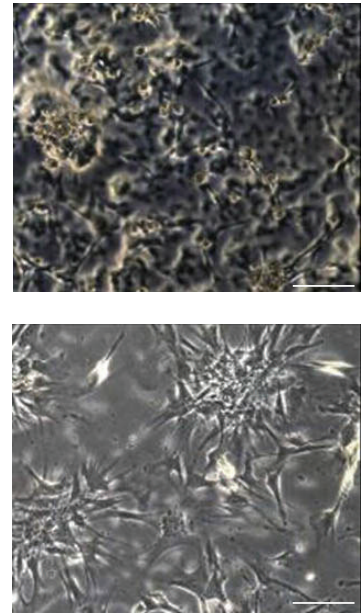

(c)
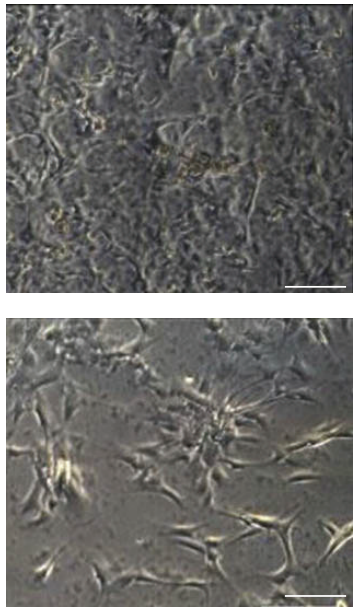

(d)

FIGURE 7: Image of C2C12 cells and hMSCs' proliferation on different films with varying surface roughness at day 3. Obviously, low surface roughness facilitated the proliferation for $\mathrm{C} 2 \mathrm{C} 12$ cells, but the opposite case happened for hMSCs. (Size of surface roughness: (a) $<$ (b) < (c) < (d), and scale bars stand for $200 \mu \mathrm{m}$ ). (Adapted with permission from [5]. Copyright 2011 Elsevier Ltd).

stability of dental and orthopedic prostheses, and critical aspects especially in aging patients with poor bone support.

3.4. Surface Charge. As to the concept of "surface properties," it involves so many aspects, and surface charge is vital factor to affect the cells' adhesion and activities. For example, the fact that electrostatic interaction (zeta potential) could have a great impact on different protein adsorption and cellular uptake of nanoparticles was demonstrated by Patil et al. [87]. Moreover, Cai et al. investigated the influence of titanium thin films' surface chemistry and surface electric charge properties on protein adsorption and cell proliferation. For purpose of producing surface with different surface charge, different functional groups, such as $-\mathrm{NH}_{2}$ or $-\mathrm{COOH}$, were functionalized on the surface of titanium film [88]. Finally, they concluded the lower the zeta-potential of functionalized titanium films, the lower the adsorption of fibrinogen [89]. Similarly, Chung et al. made a research on the influence of surface charge on high-performance cellular uptake and cytotoxicity of mesoporous silica nanoparticles in human mesenchymal stem cells. The tested surface was modified by especial chloride, and they determined the uptake of mesoporous silica nanoparticles using flow cytometry. In addition to human mesenchymal stem cells, 3T3-L1 cells were also employed for a contrast in terms of uptake behavior between different cells. In the end, they found that there was a distinct relationship between surface charge and cells' event. Additionally, as with the cells' response of MSNs charged positively, inhibition action was observed in 3T3-L1 cells but not in the case of human mesenchymal stem cells; moreover, a qualitative control could be made on the human mesenchymal stem with regard to their uptake behavior [89].

3.5. Surface Roughness. The effect of surface roughness on cells' behavior and activity has been investigated. Due to contact with the host tissue directly, the surface roughness of the nanostructured implants has a great potential influence on cells' response. For instance, the effect of surface roughness and calcium phosphate coating on the bone response of titanium implants was investigated by Hayakawa et al. [90]. Titanium implants with different kinds of surface roughness were implanted into left and right tibial diaphysis and femoral condyles of the rabbits. In the end, they considered that, from the point of healing effect, a sputtered calcium phosphate coating on an implant performed best in terms of the bone response. Certainly, the conditions of implant surface and local implant site made a combined interaction on the final bone behavior. In addition, Hu et al. studied the effect of surface roughness on the myogenic and osteogenic differentiation of cells on silk-elastin biomaterials [5]. They regulated the surface roughness of materials by adjusting the ratio of tropoelastin and silk. Specifically, $\mathrm{Hu}$ et al. prepared several thick films with different surface roughness and then cultured human bone marrow stem cells on different films to observe the effect of surface roughness on the proliferation of $\mathrm{C} 2 \mathrm{C} 12$ cells and hMSCs. They concluded that low surface roughness and high stiffness in the silk-tropoelastin materials promoted proliferation and myogenic differentiation of $\mathrm{C} 2 \mathrm{C} 12$ cells. In contrast, high surface roughness with micro/nanoscale surface patterns was favored by hMSCs (Figure 7).

Moreover, the influence of surface roughness of the titanium alloy Ti6Al4V on human bone marrow cells' response and protein adsorption was studied by Deligianni et al. [91]. They deemed that cell attachment and proliferation were positively proportional to the roughness of $\mathrm{Ti}$ alloy; also, a larger amount of total protein and fibronectin existed on rough substratum, finally, precisely because of the distinction of adsorption in two proteins above on Ti alloy with different surface roughness, leading to the different condition in cell attachment. What is more, a rigorous study of osteoblasts and 
fibroblasts' response to surface roughness was conducted by Kunzler et al. using the method of gradients of surface roughness [92]. For the purpose of forming roughness gradients, which included a wide range of roughness values, they created a specific modification process on the substratum. Calvarial osteoblasts and human gingival fibroblasts were experiments cells for studying the influence of surface roughness on cells' activity and event. Eventually, an obviously increased calvarial osteoblasts cell proliferation emerged with increasing surface roughness. However, human gingival fibroblasts took on contrary proliferation behavior, that is to say, proliferation decreasing with increasing roughness. Consequently, it fully illustrated that the response of cells to surface roughness is different depending on the cell type.

\section{Conclusion and Prospective}

In last several years, the development of approaches to repair bone defect has obtained great progress, one of most reasons of that is the appearance of novel nanomaterials with kinds of outstanding performance, and more excellent nanostructured implants are being on the way to be born. Despite the fact that nanostructured implants have great advantages in promoting cells' response and bone formation, a potential tremendous hidden danger still exists in using nanostructured implant. First of all, whether the nanoparticles are safe or dangerous is an issue being discussed constantly. Once put into our body, it cannot be guaranteed that implants containing nanoparticles are safe enough; even if they are safe themselves, due to long time of embedding in the surroundings of tissue, nanostructured implants will release certain nanophase particles that possibly do harm to our body. Moreover, the potential biohazards of nanosized wear particles at bone-prosthesis interface are also an important event necessary to be considered. However, the trend of nanostructured implant cannot be stopped, and the direction of future research is to get needed cell behavior by means of controlling the microstructure of implants. It has been shown that each of the above individual parameters can have a significant effect on the structure and function of adsorbed specific protein and biomolecule. Only if we have a good learning of relationship between surface properties and cells' response, can we create novel nanobiomaterials with needed structures. Clearly, more investigation on the toxicity of nanophase materials should be carried out, aiming to make accurate comparisons with conventionally sized particles in determining their potential toxicity. All in all, in spite of kinds of challenges ahead, sorts of fact proved that nanophase materials represent an important growing area of research that may improve bonding between an implant and surrounding bone. We firmly believe nanostructured implant with various surface properties will have an extremely bright future in improving orthopedic implant efficacy.

\section{Conflict of Interests}

The authors have no conflict of interests.

\section{Authors' Contribution}

Feng Zhao and Jian Wang contributed equally to this work.

\section{References}

[1] M.-H. Cheng, E. M. Brey, A. Allori et al., "Ovine model for engineering bone segments," Tissue Engineering, vol. 11, no. 1-2, pp. 214-225, 2005.

[2] M. J. Miller, "Osseous tissue engineering in oncologic surgery," Seminars in Surgical Oncology, vol. 19, no. 3, pp. 294-301, 2000.

[3] E. Palin, H. Liu, and T. J. Webster, "Mimicking the nanofeatures of bone increases bone-forming cell adhesion and proliferation," Nanotechnology, vol. 16, no. 9, pp. 1828-1835, 2005.

[4] P. Bills, L. Brown, X. Jiang, and L. Blunt, "A metrology solution for the orthopaedic industry," Journal of Physics: Conference Series, vol. 13, no. 1, pp. 316-319, 2005.

[5] X. Hu, S.-H. Park, E. S. Gil, X.-X. Xia, A. S. Weiss, and D. L. Kaplan, "The influence of elasticity and surface roughness on myogenic and osteogenic-differentiation of cells on silk-elastin biomaterials," Biomaterials, vol. 32, no. 34, pp. 8979-8989, 2011.

[6] X. Li, L. Wang, Y. Fan, Q. Feng, F.-Z. Cui, and F. Watari, "Nanostructured scaffolds for bone tissue engineering," Journal of Biomedical Materials Research Part A, vol. 101, no. 8, pp. 24242435, 2013.

[7] C. Nelson, A. Magge, T. S. Bernard, Y. Khan, and C. T. Laurencin, "Nanostructured composites for bone repair," Journal of Biomaterials and Tissue Engineering, vol. 3, no. 4, pp. 426-439, 2013.

[8] C. M. Niemeyer, "Nanoparticles, proteins, and nucleic acids: biotechnology meets materials science," Angewandte ChemieInternational Edition, vol. 40, no. 22, pp. 4128-4158, 2001.

[9] D. Cui and H. Gao, "Advance and prospect of bionanomaterials," Biotechnology Progress, vol. 19, no. 3, pp. 683-692, 2003.

[10] X. Li, Y. Fan, and F. Watari, "Current investigations into carbon nanotubes for biomedical application," Biomedical Materials, vol. 5, no. 2, Article ID 022001, 2010.

[11] G. M. Whitesides, "The "right" size in nanobiotechnology," Nature Biotechnology, vol. 21, no. 10, pp. 1161-1165, 2003.

[12] T. A. Desai, "Micro- and nanoscale structures for tissue engineering constructs," Medical Engineering \& Physics, vol. 22, no. 9, pp. 595-606, 2001.

[13] X. Li, X. Liu, J. Huang, Y. Fan, and F.-Z. Cui, "Biomedical investigation of CNT based coatings," Surface and Coatings Technology, vol. 206, no. 4, pp. 759-766, 2011.

[14] L. A. Bauer, N. S. Birenbaum, and G. J. Meyer, "Biological applications of high aspect ratio nanoparticles," Journal of Materials Chemistry, vol. 14, no. 4, pp. 517-526, 2004.

[15] L. Mazzola, "Commercializing nanotechnology", Nature Biotechnology, vol. 21, no. 10, pp. 1137-1143, 2003.

[16] X. Li, H. Liu, X. Niu et al., "Osteogenic differentiation of human adipose-derived stem cells induced by osteoinductive calcium phosphate ceramics," Journal of Biomedical Materials Research Part B: Applied Biomaterials, vol. 97, no. 1, pp. 10-19, 2011.

[17] K. L. Lee, G. A. Ngai, S. C. Varghese, L. Duan, and J. A. Cooper, "Nanostructures for ligament and tendon regeneration," Journal of Biomaterials and Tissue Engineering, vol. 3, no. 4, pp. 409-425, 2013.

[18] J. Wang, "Nanomaterial-based amplified transduction of biomolecular interactions," Small, vol. 1, no. 11, pp. 1036-1043, 2005. 
[19] M. C. Powell and M. S. Kanarek, "Nanomaterial health effectspart 1: background and current knowledge," Wisconsin Medical Journal, vol. 105, no. 2, pp. 16-20, 2006.

[20] J. M. Slocik and R. R. Naik, "Probing peptide-nanomaterial interactions," Chemical Society Reviews, vol. 39, no. 9, pp. 34543463, 2010.

[21] F. S. Kaplan, W. C. Hayes, T. M. Keaveny et al., "Form and function of bone," in Orthopaedic Basic Science, pp. 127-184, American Academy of Orthopaedic Surgery, Rosemont, Ill, USA, 1994.

[22] T. J. Webster, C. Ergun, R. H. Doremus, R. W. Siegel, and R. Bizios, "Enhanced functions of osteoblasts on nanophase ceramics," Biomaterials, vol. 21, no. 17, pp. 1803-1810, 2000.

[23] T. J. Webster and J. U. Ejiofor, "Increased osteoblast adhesion on nanophase metals: Ti, Ti6Al4V, and CoCrMo," Biomaterials, vol. 25, no. 19, pp. 4731-4739, 2004.

[24] T. J. Webster and T. A. Smith, "Increased osteoblast function on PLGA composites containing nanophase titania," Journal of Biomedical Materials Research Part A, vol. 74, no. 4, pp. 677-686, 2005.

[25] S. M. Moghimi and J. Szebeni, "Stealth liposomes and long circulating nanoparticles: critical issues in pharmacokinetics, opsonization and protein-binding properties," Progress in Lipid Research, vol. 42, no. 6, pp. 463-478, 2003.

[26] X. Li, Y. Yang, Y. Fan, Q. Feng, F.-Z. Cui, and F. Watari, "Biocomposites reinforced by fibers or tubes as scaffolds for tissue engineering or regenerative medicine," Journal of Biomedical Materials Research Part A, vol. 102, no. 5, pp. 1580-1594, 2014.

[27] Q. A. Pankhurst, J. Connolly, S. K. Jones, and J. Dobson, "Applications of magnetic nanoparticles in biomedicine," Journal of Physics D: Applied Physics, vol. 36, no. 13, pp. R167-R181, 2003.

[28] M. O. Oyewumi and R. J. Mumper, "Influence of formulation parameters on gadolinium entrapment and tumor cell uptake using folate-coated nanoparticles," International Journal of Pharmaceutics, vol. 251, no. 1-2, pp. 85-97, 2003.

[29] S. M. Moghimi, A. C. Hunter, and J. C. Murray, "Longcirculating and target-specific nanoparticles: theory to practice," Pharmacological Reviews, vol. 53, no. 2, pp. 283-318, 2001.

[30] K. C. Dee, D. A. Puleo, and R. Bizios, An Introduction to TissueBiomaterial Interactions, John Wiley \& Sons, Hoboken, NJ, USA, 2002.

[31] M. Tulinski and M. Jurczyk, "Nanostructured nickel-free austenitic stainless steel/hydroxyapatite composites," Journal of Nanoscience and Nanotechnology, vol. 12, no. 11, pp. 8779-8782, 2012.

[32] J. E. Gagner, S. Shrivastava, X. Qian, J. S. Dordick, and R. W. Siegel, "Engineering nanomaterials for biomedical applications requires understanding the nano-bio interface: a perspective," The Journal of Physical Chemistry Letters, vol. 3, no. 21, pp. 31493158, 2012.

[33] Y. W. Chun and T. J. Webster, "The role of nanomedicine in growing tissues," Annals of Biomedical Engineering, vol. 37, no. 10, pp. 2034-2047, 2009.

[34] L. Zhang and T. J. Webster, "Nanotechnology and nanomaterials: promises for improved tissue regeneration," Nano Today, vol. 4, no. 1, pp. 66-80, 2009.

[35] H. Peng, X. Liu, R. Wang, F. Jia, L. Dong, and Q. Wang, "Emerging nanostructured materials for musculoskeletal tissue engineering," Journal of Materials Chemistry B, vol. 2, no. 38, pp. 6435-6461, 2014.
[36] S. B. Kennedy, N. R. Washburn, C. G. Simon Jr., and E. J. Amis, "Combinatorial screen of the effect of surface energy on fibronectin-mediated osteoblast adhesion, spreading and proliferation," Biomaterials, vol. 27, no. 20, pp. 3817-3824, 2006.

[37] B. D. Boyan, C. H. Lohmann, D. D. Dean, V. L. Sylvia, D. L. Cochran, and Z. Schwartz, "Mechanisms involved in osteoblast response to implant surface morphology," Annual Review of Materials Science, vol. 31, pp. 357-371, 2001.

[38] D. A. Puleo and A. Nanci, "Understanding and controlling the bone-implant interface," Biomaterials, vol. 20, no. 23-24, pp. 2311-2321, 1999.

[39] K. Anselme and M. Bigerelle, "Statistical demonstration of the relative effect of surface chemistry and roughness on human osteoblast short-term adhesion," Journal of Materials Science: Materials in Medicine, vol. 17, no. 5, pp. 471-479, 2006.

[40] A. M. Cortizo, "Effect of surface topography of collagen scaffolds on cytotoxicity and osteoblast differentiation," Journal of Biomaterials and Tissue Engineering, vol. 8, pp. 125-132, 2012.

[41] X. Li, Y. Huang, L. Zheng et al., "Effect of substrate stiffness on the functions of rat bone marrow and adipose tissue derived mesenchymal stem cells in vitro," Journal of Biomedical Materials Research Part A, vol. 102, no. 4, pp. 1092-1101, 2014.

[42] K. Lee, Y.-H. Jeong, Y.-M. Ko, H.-C. Choe, and W. A. Brantley, "Hydroxyapatite coating on micropore-formed titanium alloy utilizing electrochemical deposition," Thin Solid Films, vol. 549, pp. 154-158, 2013.

[43] A. Ballo, H. Agheli, J. Lausmaa, P. Thomsen, and S. Petronis, "Nanostructured model implants for in vivo studies: influence of well-defined nanotopography on de novo bone formation on titanium implants," International Journal of Nanomedicine, vol. 6, pp. 3415-3428, 2011.

[44] R. L. Price, K. Ellison, K. M. Haberstroh, and T. J. Webster, "Nanometer surface roughness increases select osteoblast adhesion on carbon nanofiber compacts," Journal of Biomedical Materials Research Part A, vol. 70, no. 1, pp. 129-138, 2004.

[45] K. Mustafa, A. Odén, A. Wennerberg, K. Hultenby, and K. Arvidson, "The influence of surface topography of ceramic abutments on the attachment and proliferation of human oral fibroblasts," Biomaterials, vol. 26, no. 4, pp. 373-381, 2005.

[46] R. J. Vance, D. C. Miller, A. Thapa, K. M. Haberstroh, and T. J. Webster, "Decreased fibroblast cell density on chemically degraded poly-lactic-co-glycolic acid, polyurethane, and polycaprolactone," Biomaterials, vol. 25, no. 11, pp. 2095-2103, 2004.

[47] X. Li, C. A. van Blitterswijk, Q. Feng, F. Cui, and F. Watari, "The effect of calcium phosphate microstructure on bone-related cells in vitro," Biomaterials, vol. 29, no. 23, pp. 3306-3316, 2008.

[48] K. Webb, V. Hlady, and P. A. Tresco, "Relationships among cell attachment, spreading, cytoskeletal organization, and migration rate for anchorage-dependent cells on model surfaces," Journal of Biomedical Materials Research, vol. 49, no. 3, pp. 362368, 2000.

[49] H. Liao, A. S. Andersson, D. Sutherland, S. Petronis, B. Kasemo, and P. Thomsen, "Response of rat osteoblast-like cells to microstructured model surfaces in vitro," Biomaterials, vol. 24, no. 4, pp. 649-654, 2003.

[50] X. Li, Q. Feng, X. Liu, W. Dong, and F. Cui, "Collagen-based implants reinforced by chitin fibres in a goat shank bone defect model," Biomaterials, vol. 27, no. 9, pp. 1917-1923, 2006.

[51] J. K. Koper and J. Jakubowicz, "Correlation of wettability with surface structure and morphology of the anodically oxidized titanium implants," Journal of Biomaterials and Tissue Engineering, vol. 4, no. 6, pp. 459-464, 2014. 
[52] X. Liu and P. X. Ma, "Polymeric scaffolds for bone tissue engineering," Annals of Biomedical Engineering, vol. 32, no. 3, pp. 477-486, 2004.

[53] M. Wang, Y. Wang, Y. Chen, and H. Gu, "Improving endothelialization on 316L stainless steel through wettability controllable coating by sol-gel technology," Applied Surface Science, vol. 268, pp. 73-78, 2013.

[54] S. Kay, A. Thapa, K. M. Haberstroh, and T. J. Webster, "Nanostructured polymer/nanophase ceramic composites enhance osteoblast and chondrocyte adhesion," Tissue Engineering, vol. 8, no. 5, pp. 753-761, 2002.

[55] J. M. Macak, H. Tsuchiya, A. Ghicov et al., " $\mathrm{TiO}_{2}$ nanotubes: Self-organized electrochemical formation, properties and applications," Current Opinion in Solid State and Materials Science, vol. 11, no. 1-2, pp. 3-18, 2007.

[56] K. Cai, J. Bossert, and K. D. Jandt, "Does the nanometre scale topography of titanium influence protein adsorption and cell proliferation?" Colloids and Surfaces B: Biointerfaces, vol. 49, no. 2, pp. 136-144, 2006.

[57] A. Palmquist, H. Engqvist, J. Lausmaa, and P. Thomsen, "Commercially available dental implants: review of their surface characteristics," Journal of Biomaterials and Tissue Engineering, vol. 2, no. 2, pp. 112-124, 2012.

[58] A. A. Campbell, "Bioceramics for implant coatings," Materials Today, vol. 6, no. 11, pp. 26-30, 2003.

[59] X. Li, H. Gao, M. Uo et al., "Maturation of osteoblast-like SaoS2 induced by carbon nanotubes," Biomedical Materials, vol. 4, no. 1, Article ID 015005, 2009.

[60] S. Facca, D. Lahiri, F. Fioretti et al., "In vivo osseointegration of nano-designed composite coatings on titanium implants," ACS Nano, vol. 5, no. 6, pp. 4790-4799, 2011.

[61] K. Balani, R. Anderson, T. Laha et al., "Plasma-sprayed carbon nanotube reinforced hydroxyapatite coatings and their interaction with human osteoblasts in vitro," Biomaterials, vol. 28, no. 4, pp. 618-624, 2007.

[62] D. Lahiri, A. P. Benaduce, F. Rouzaud et al., "Wear behavior and in vitro cytotoxicity of wear debris generated from hydroxyapatite-carbon nanotube composite coating," Journal of Biomedical Materials Research Part A, vol. 96, no. 1, pp. 1-12, 2011.

[63] X. Li, H. Liu, X. Niu et al., "The use of carbon nanotubes to induce osteogenic differentiation of human adipose-derived MSCs in vitro and ectopic bone formation in vivo," Biomaterials, vol. 33, no. 19, pp. 4818-4827, 2012.

[64] K. C. Popat, R. H. Daniels, R. S. Dubrow, V. Hardev, and T. A. Desai, "Nanostructured surfaces for bone biotemplating applications," Journal of Orthopaedic Research, vol. 24, no. 4, pp. 619-627, 2006.

[65] K. C. Popat, L. Leoni, C. A. Grimes, and T. A. Desai, "Influence of engineered titania nanotubular surfaces on bone cells," Biomaterials, vol. 28, no. 21, pp. 3188-3197, 2007.

[66] E. E. L. Swan, K. C. Popat, C. A. Grimes, and T. A. Desai, "Fabrication and evaluation of nanoporous alumina membranes for osteoblast culture," Journal of Biomedical Materials Research Part A, vol. 72, no. 3, pp. 288-295, 2005.

[67] X. M. Li, W. Liu, L. W. Sun et al., "Effects of physicochemical properties of nanomaterials on their toxicity," Journal of Biomedical Materials Research Part A, 2015.

[68] J. Park, S. Bauer, K. A. Schlegel, F. W. Neukam, K. D. von Mark, and P. Schmuki, " $\mathrm{TiO}_{2}$ nanotube surfaces: $15 \mathrm{~nm}$-an optimal length scale of surface topography for cell adhesion and differentiation," Small, vol. 5, no. 6, pp. 666-671, 2009.
[69] J. Park, S. Bauer, K. von der Mark, and P. Schmuki, "Nanosize and vitality: $\mathrm{TiO}_{2}$ nanotube diameter directs cell fate," Nano Letters, vol. 7, no. 6, pp. 1686-1691, 2007.

[70] S. Oh, K. S. Brammer, Y. S. J. Li et al., "Stem cell fate dictated solely by altered nanotube dimension," Proceedings of the National Academy of Sciences of the United States of America, vol. 106, no. 7, pp. 2130-2135, 2009.

[71] K. S. Brammer, C. J. Frandsen, and S. Jin, " $\mathrm{TiO}_{2}$ nanotubes for bone regeneration," Trends in Biotechnology, vol. 30, no. 6, pp. 315-322, 2012.

[72] S. Guizzardi, C. Galli, D. Martini et al., "Different titanium surface treatment influences human mandibular osteoblast response," Journal of Periodontology, vol. 75, no. 2, pp. 273-282, 2004.

[73] K. Anselme and M. Bigerelle, "Topography effects of pure titanium substrates on human osteoblast long-term adhesion," Acta Biomaterialia, vol. 1, no. 2, pp. 211-222, 2005.

[74] X. Li, X. Liu, W. Dong et al., "In vitro evaluation of porous poly(L-lactic acid) scaffold reinforced by chitin fibers," Journal of Biomedical Materials Research-Part B Applied Biomaterials, vol. 90, no. 2, pp. 503-509, 2009.

[75] M.-J. Kim, M.-U. Choi, and C.-W. Kim, "Activation of phospholipase D1 by surface roughness of titanium in MG63 osteoblastlike cell," Biomaterials, vol. 27, no. 32, pp. 5502-5511, 2006.

[76] J.-W. Park, I.-S. Jang, and J.-Y. Sun, "Bone response to endosseous titanium implants surface-modified by blasting and chemical treatment: a histomorphometric study in the rabbit femur," Journal of Biomedical Materials Research Part B: Applied Biomaterials, vol. 84, no. 2, pp. 400-407, 2008.

[77] H. Daugaard, B. Elmengaard, J. E. Bechtold, and K. Soballe, "Bone growth enhancement in vivo on press-fit titanium alloy implants with acid etched microtexture," Journal of Biomedical Materials Research-Part A, vol. 87, no. 2, pp. 434-440, 2008.

[78] R. Celletti, V. C. Marinho, T. Traini et al., "Bone contact around osseointegrated implants: a histologic study of acid-etched and machined surfaces," Journal of Long-Term Effects of Medical Implants, vol. 16, no. 2, pp. 131-143, 2006.

[79] H. Liu and T. J. Webster, "Nanomedicine for implants: a review of studies and necessary experimental tools," Biomaterials, vol. 28, no. 2, pp. 354-369, 2007.

[80] X. Li, H. Gao, M. Uo et al., "Effect of carbon nanotubes on cellular functions in vitro," Journal of Biomedical Materials Research Part A, vol. 91, no. 1, pp. 132-139, 2009.

[81] G. Mendonça, D. B. S. Mendonça, F. J. L. Aragão, and L. F. Cooper, "Advancing dental implant surface technology: from micron-to nanotopography," Biomaterials, vol. 29, no. 28, pp. 3822-3835, 2008.

[82] F. Varíola, F. Vetrone, L. Richert et al., "Improving biocompatibility of implantable metals by nanoscale modification of surfaces: an overview of strategies, fabrication methods, and challenges," Small, vol. 5, no. 9, pp. 996-1006, 2009.

[83] F. Variola, J. B. Brunski, G. Orsini, P. T. de Oliveira, R. Wazen, and A. Nanci, "Nanoscale surface modifications of medically relevant metals: State-of-the art and perspectives," Nanoscale, vol. 3, no. 2, pp. 335-353, 2011.

[84] F. Variola, J.-H. Yi, L. Richert, J. D. Wuest, F. Rosei, and A. Nanci, "Tailoring the surface properties of Ti6Al4V by controlled chemical oxidation," Biomaterials, vol. 29, no. 10, pp. 1285-1298, 2008.

[85] X. Liu, X. Li, Y. Fan et al., "Repairing goat tibia segmental bone defect using scaffold cultured with mesenchymal stem 
cells," Journal of Biomedical Materials Research Part B: Applied Biomaterials, vol. 94, no. 1, pp. 44-52, 2010.

[86] R. E. McMahon, L. Wang, R. Skoracki, and A. B. Mathur, "Development of nanomaterials for bone repair and regeneration," Journal of Biomedical Materials Research Part B Applied Biomaterials, vol. 101, no. 2, pp. 387-397, 2013.

[87] S. Patil, A. Sandberg, E. Heckert, W. Self, and S. Seal, "Protein adsorption and cellular uptake of cerium oxide nanoparticles as a function of zeta potential," Biomaterials, vol. 28, no. 31, pp. 4600-4607, 2007.

[88] K. Cai, M. Frant, J. Bossert, G. Hildebrand, K. Liefeith, and K. D. Jandt, "Surface functionalized titanium thin films: zetapotential, protein adsorption and cell proliferation," Colloids and Surfaces B: Biointerfaces, vol. 50, no. 1, pp. 1-8, 2006.

[89] T.-H. Chung, S.-H. Wu, M. Yao et al., "The effect of surface charge on the uptake and biological function of mesoporous silica nanoparticles in 3T3-L1 cells and human mesenchymal stem cells," Biomaterials, vol. 28, no. 19, pp. 2959-2966, 2007.

[90] T. Hayakawa, M. Yoshinari, K. Nemoto, J. G. C. Wolke, and J. A. Jansen, "Effect of surface roughness and calcium phosphate coating on the implant/bone response," Clinical Oral Implants Research, vol. 11, no. 4, pp. 296-304, 2000.

[91] D. D. Deligianni, N. Katsala, S. Ladas, D. Sotiropoulou, J. Amedee, and Y. F. Missirlis, "Effect of surface roughness of the titanium alloy Ti-6Al-4V on human bone marrow cell response and on protein adsorption," Biomaterials, vol. 22, no. 11, pp. 1241-1251, 2001.

[92] T. P. Kunzler, T. Drobek, M. Schuler, and N. D. Spencer, "Systematic study of osteoblast and fibroblast response to roughness by means of surface-morphology gradients," Biomaterials, vol. 28, no. 13, pp. 2175-2182, 2007. 

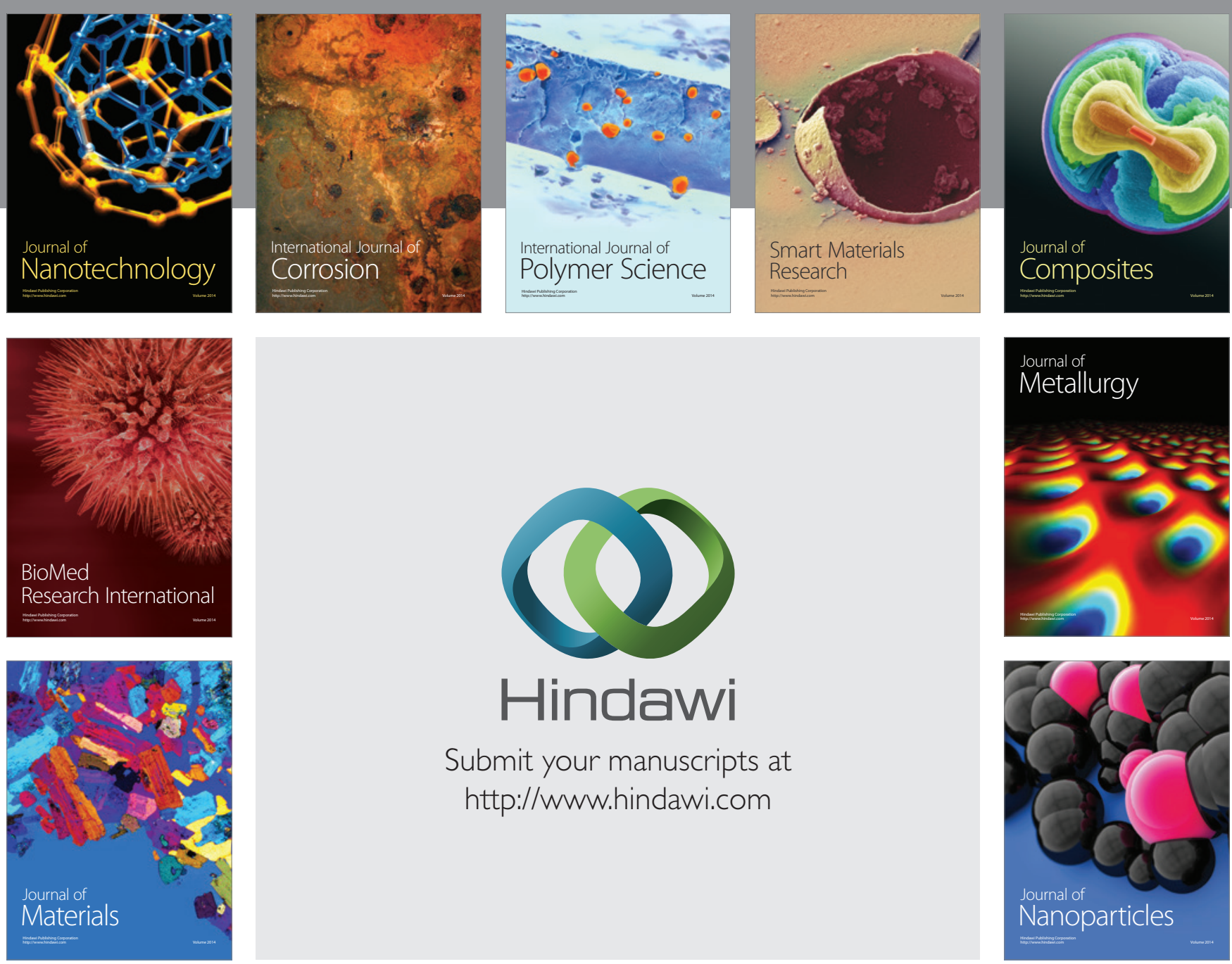

Submit your manuscripts at http://www.hindawi.com
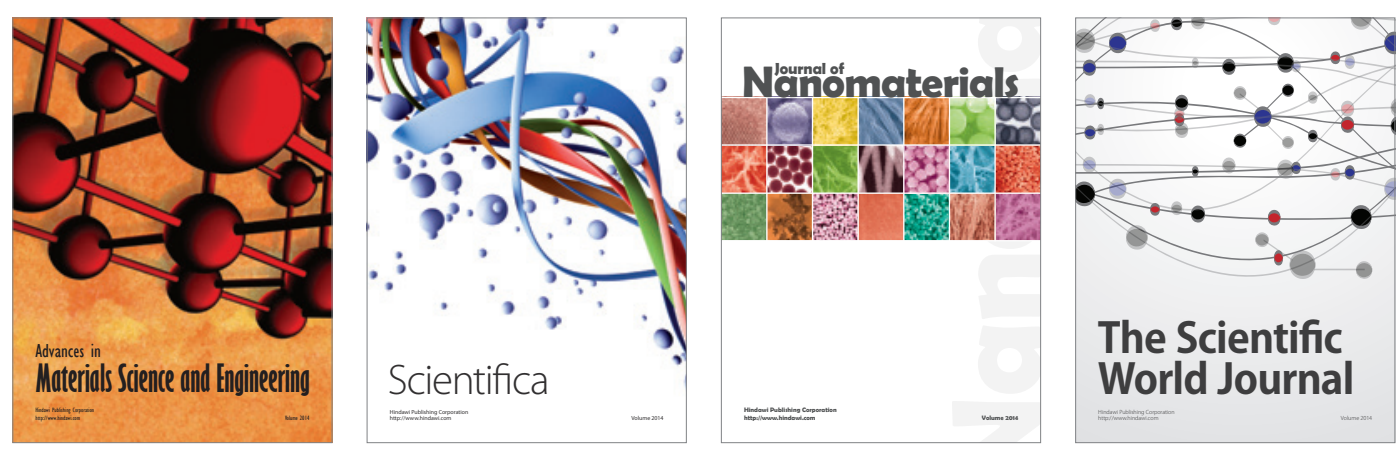

\section{The Scientific World Journal}
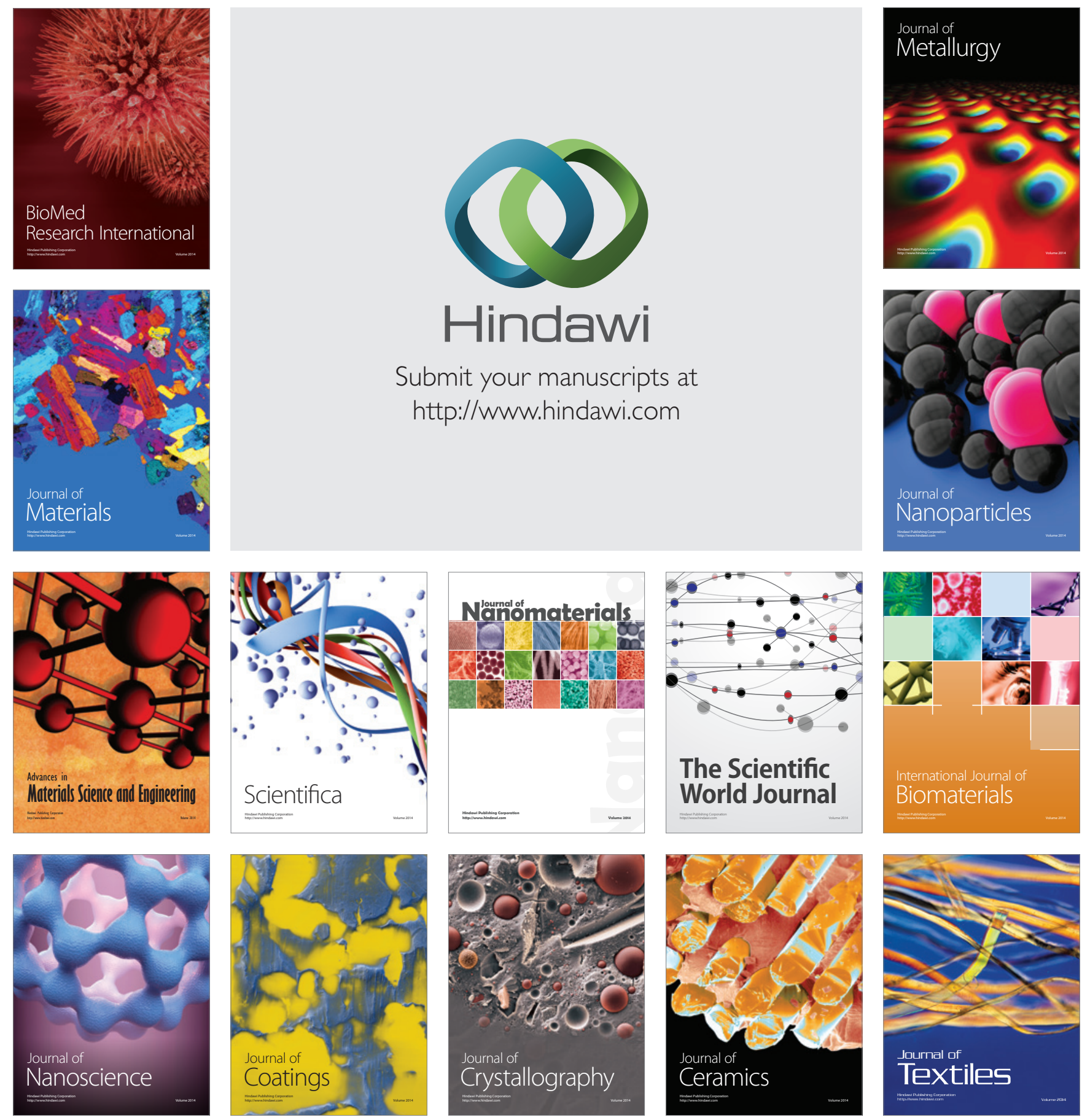